\title{
Virtues and Health: A New Perspective of Bioethics from the Horizon of Confucianism Ethics
}

\author{
Kuangfei Xie \\ Humanity and Politics Department, Nanjing University of Traditional Chinese Medicine, Nan Jing, China
}

Email address:

43806885@qq.com,09110010012@fudan.edu.cn

To cite this article:

Kuangfei Xie. Virtues and Health: A New Perspective of Bioethics from the Horizon of Confucianism Ethics. International Journal of Philosophy. Vol. 3, No. 5, 2015, pp. 47-51.doi: 10.11648/j.ijp.20150305.11

\begin{abstract}
Virtues constitute the fundamental foundation of health, which consists of the physical health, mental health and the spiritual health. By building the virtues and characters, we remove the wrong and misleading beliefs from the mind so that we can maintain the health. The misunderstandings and misinterpretations about what man is have directly resulted in the severe health crisis of the modern man. Philosophically considered, man as a whole is composed of the physical body, the mental mind and the spiritual soul. Virtues make it possible for us to restore man as a whole and healthy person.
\end{abstract}

Keywords: Virtues, Health, Confucianism Ethics

\section{Introduction}

Health is definitely a comprehensive concept. To be healthy means not only the physical health, but also the mental health and the spiritual health. The essential meaning of Bioethics is the ethics concerning the ethics of the whole life. Too much emphasis upon the technical or scientific dimension of Bioethics or medical science itself has resulted in the severe modern health crisis in spite of the amazingly rapid development of modern medical technologies.

Generally speaking, by providing the morally and virtuously based guidance on the essential aspects of human health, virtues, without a doubt, consistently constitute the most fundamental foundation of the health of mankind.

\section{Prevention Is Better than Cure: The Essential Function of Virtues}

Undoubtedly, virtue ethics belongs to the practical ethics. Not only should it serve the purpose of persuading as many people as possible to engage in the thinking about virtues, but also it needs to provide the effective guidance about how to live a good life with both a sound body and a sound mind. Nowadays, most of the diseases of the modern people have not been caused by the lack of nutrition or the physical reasons, but by the unhealthy lifestyle and the mental disorders, such as anxiety and too much pressure. If the wrong and misleading beliefs are not removed by building the solid virtues, people would not be really healthy. Moreover, virtues can essentially implant healthy and sound mentality into the minds of the virtuous agents, which plays an indispensable role in the shaping of the healthy life." The crucial factor in gaining health of the mind lies in forming a correct understanding of the proper goal of human life, which can then shape the whole pattern of a person's beliefs, emotions, and desires."[1] The source of the tangible illnesses, is, undoubtedly, the intangible mental or spiritual diseases. The best way to cure the diseases is to prevent them from happening at the very first beginning. After all, the question of health is inextricably interwoven with the essential issue of virtues. Living virtuously and being virtuous are not only a subject of moral choice or alternative; it is closely linked with the mental and spiritual immunization ability which has much to do with the health of mankind. Health is not only a physical state of life, but also a mental and spiritual state of life. By inculcating the fundamental virtues, such as honesty, integrity, temperance, tolerance, into the minds, the virtuous agents are capable of forming the sound lifestyle and dispositions, which can do great good to their overall health.

With the rapid and inevitable development of the social division aiming at the never-ending high efficiency, health seems to be the duty of doctors or hospitals. Every individual does not need to be emotionally and virtuously responsible for his own health. But in its earliest stages the medical philosophy was not only concerned with the physical universe of the human beings, but also with the universe of man as a whole. And it's not only the professional doctors that were 
responsible for the health of the people, but also the people themselves who shouldered the responsibility of health by either consciously choosing the culturally healthy lifestyle or by constantly improving his mindset. At that time, it was commonly acknowledged that it was virtually impossible to penetrate into the secret of health without having understood the innermost universe of man.

\subsection{What Is Man? The Virtue Perspective}

To essentially understand the issue of health, first and foremost, we need to understand what man is. Is man only the body? Or the mind? Or the spirit? Or the soul? Or the proper combination of them ? As a matter of fact, the popular misunderstandings and misinterpretations with regard of the question of what man is have directly resulted in the severe health crisis of the modern man. Philosophically considered, man as a whole is composed of the physical body, the mental mind and the spiritual soul. Correspondingly, the whole and harmonious health of a person is also composed of three inseparable but distinct parts: the physical health, the mental health and the spiritual health. In fact, the psychological dimension and the virtuous dimension of health are always so pervaded with the health of human life that there is something of personality or virtue in all and in every particular aspect of the wisdom of health. "Man is declared to be that creature who is constantly in search of himself, a creature who in every moment of his existence must examine and scrutinize the conditions of his existence. We must actually confront man, we must meet him squarely face to face, in order to understand him."[2] Essentially speaking, the definition of man can only be found in the complicated social relationship existing around man. The wisdom of man is definitely not the science of man. Physical things may be studied and examined in terms of their tangible and measurable characteristics, but man must be understood and defined in terms of the emotions and virtues.

The health of man is not an isolated issue, similarly, the essence of man can not be regarded simply as the scientific monologue, but as the humanitarian and meaningful ongoing dialogues. The health of the man does not depend solely on the external conditions, such as the living conditions and the medical equipments, but on the inner harmony and inner peace of the mind and soul. The subjective feelings, or the emotional and mental state of the moral agents, certainly have tremendous effects upon their health.

\subsection{Overcoming Oneself: The Virtuous Road to Health}

Ultimately, it is the human being himself that is mainly responsible for his health. Virtue is never entirely inborn, but the natural result of constant nurturing and cultivating. Just one confident act can not make a truly confident person, and just one tolerant act can not make a tolerant person. Virtue is an ongoing process of moral self-improvement. To cultivate virtues, we need to overcome and conquer the vices inherent in the human nature.

The modern people are surrounded by all kinds of temptations associated with pains and pleasures. If we are unable to overcome ourselves, we will be distracted from habits of virtue and the virtues that we have formed will be corrupted by the temptations. In fact, the greatest temptation facing the modern people is the temptation to be a nihilist: doubting everything and trusting nothing. The ruining of traditional values and virtues has been predicted by the existentialists such as Nietzsche and Kierkegaard. When God is dead, everything would be allowed. With the breakdown of the traditional values and virtues comes the prevalent mental plagues of the present era, namely, the loneliness, despair, emptiness, and the never-ending anxiety or helplessness, which, combined together, have contributed a lot to the worsening of the health crisis of the modern people.

In contrast to the incredible advances in the science and technology, there is no parallel advance in the inner universe of mankind. The modern people are faced with the serious identity crisis. They are confused and puzzled about who they truly are. Besides, the inevitable process of dehumanizing and alienation has made it increasingly difficult for the modern people to overcome themselves and be themselves. Man is becoming a stranger to himself and his body is only an external tool that is utilized to satisfy his insatiable sensual desires. In a word, man has made himself a slave of the science and technology that he has made.

Among the many difficulties or challenges confronting the modern people, not the least has been the lack of moral courage to overcome the cowardly side of the human nature. Owing to the excessive greed and luxury, the modern people are never satisfied with what they have; they are never content. They are degenerated and degraded into the slaves of their insatiable desires. As a consequence, the modern people have forgotten the sense of gratitude and appreciation, which inevitably lead to the never-ending complaints. And the complaints, anger, resentment are just the intangible but fundamental causes of the health crisis of modern people.

\subsection{Rebuilding the Inner Harmony: Virtues and Values}

When the young people are not properly equipped by virtuous education to be morally prepared for the extremely complicated social life filled with distractions and temptations, he will find that his life is so full of conflicts and contradictions that his original inner peace and harmony will be disillusioned and broken into pieces. The inner harmony is the foundation of the outer harmony. And from the perspective of the traditional Chinese medicine, living in harmony with nature, living in harmony with others, as well as living in harmony with the inner self, together, constitute the essential basis of the sustainable health.

The disunity of the modern times has been reflected in the disunity and disharmony of the inner virtuous world. Apart from the chaos and noises of the inner mental world, the hypocrisy and sentimentality of the modern era has also made the heart no more peaceful and tranquil, which also poses a serious threat to the health of the modern people.

Whereas virtues are universal and common, values are more personal and private. Only when the universal values 
have been internalized into the personal and innermost values can they really contribute tremendously to the health and happiness of the modern people. However, with the gap or gulf between the virtues and values getting deeper and broader, it is getting increasingly difficult for the modern people to rebuild the inner harmony.

\subsection{Let Virtues Be Virtues: Be Truly Healthy by Being Truly Virtuous}

The most striking fact about the moral world of modern era is that virtues or characters, and even the general morality of the whole society, have been made an intangible asset or a commodity, by which people can gain the reputation and win the trust of others. The prevalent attitude towards virtues is that the virtues have tremendous commercial values, and by pretending to be, or appearing to be virtuous before others, you can gain a lot of profits or benefits. Virtues are no longer the integral goodness, or the inner integrity of the soul that can deepen and elevate the noble emotions of dignity and mission, but the quantitative moral commodities that can be bought and sold. There are even a great many people who sell their souls to win the world. But what shall we really gain if we conquer the whole outer universe but lose and sell our inner soul universe? When virtues have been degraded into the virtuous masks, the virtues are just the hollow ones. The so-called virtuous people are just the hollow people with the soulless virtue commodity to show off and sell. In this sense, the traditional virtues have been gone with the wind and have been dead for a long time.

Just like the pollution and contamination of the natural environment can do great harm to our physical health, the corruption and pollution of our moral and virtuous world can do even greater harm to the health of our spirits and souls, which constitute the real core of our health.

By pursuing the superficial and shallow price of virtues, the modern people have lost their conviction of how vitally important the virtues are to their truly lasting and sustainable happiness. Virtues are not the ornaments of happiness and health, but the indispensable, fundamental pillars of happiness and health. It is essential for us to let virtues be virtues and rediscover the lost horizon of the genuine virtues.

\section{The Crisis of Health and the Virtue Calamity}

To a great extent, virtues are not something that stay in our minds or hearts, but a form of healthy energy that constantly stimulate us to be morally and virtuously better. Similarly, health is not something that we can just possess like an object, but a relatively stable and harmonious state of body, mind and spirit.

To let the energy of virtues and life flow smoothly and continuously, we need to revive the coherent and complete picture of the traditional virtues. Unfortunately, the modern virtues are just fragments of the originally whole picture of virtues, lacking consistency and coherence. According to the doctrine of the traditional Chinese medicine, when the natural flow of the energy of life is negatively affected or even blocked, the corresponding diseases will appear. To restore the healthy state, we need to make sure that the flow of life energy can go on smoothly. The inner flow of life energy is fundamentally determined by the inner virtues that are deeply rooted into the hearts of man.

\subsection{The Loss of the Traditional and Cultural Context of Virtues: The Fundamental Cause of the Crisis of Both Virtue and Health}

Both the virtues and the health of the modern world are in "a grave state of disorder"[3]. We are still using the superficial languages of virtue ethics, and we still possess the name list of all kinds of specific virtues, such as wisdom, generosity, tolerance, justice, and compassion, but we have essentially lost or forgotten those cultural and traditional contexts or backgrounds from which the essential significance and value of each specific virtue derived. The same is true of the medical science. We are still using conceptions such as life, health, medicine, healing, and cure, but we have forgotten what the essence or soul of life is and what man is. What makes the language of virtues powerful and meaningful is the cultural background and the social context. Likewise, what makes the language of the physical body powerful and meaningful is the virtuous background and the moral context. The originally perceived ills of modernity have been commonly felt and recognized by the public with the rapid development of globalization and integration. The body can be ill, so can be the soul. The individuals can be ill, and the society, on the whole, can also be ill. The illness of the whole society, caused largely by the modernity, sooner or later, will have great impacts upon the health of each individual. After all, just like the meaning of each word will be changed according to the alterations of the context, the conditions of each individual will also be changed based on the changes of the general social context.

\subsection{Discipline and Temperance: Confront the Challenges of Information Explosion to Be Virtuously Healthy}

Nowadays, the modern people are living, willingly or unwillingly, in the era of information explosion. They are surrounded by too many resources, especially the digital or virtual resources but they find that they are deprived of their valuable time which could have been spent living the simple but virtuous life that can do great good to their health.

Even though the originally integral and whole picture of the traditional virtues has been so fragmented and broken into pieces that can it can even no longer be clearly recognized, the modern people are still eager for the simple but meaningful and happy life. Unfortunately, too many convenient modern tools and technologies have made it almost impossible for the modern people to live the simple and virtuous life. They simply can not focus their limited time and energy on the few vitally important things, such as building the virtues restoring the inner tranquility by meditation. The explosion of the unlimited intangible resources, such as information, news, TV programmes, computer games and mobile phone games, has 
brought an unbearable mental burden to the minds and hearts of the modern people. Therefore, it is of paramount importance for every individual to train and cultivate the specific virtues of temperance and discipline. When we are physically ill, we need to go to the trained physicians to get the medical help, and when our spirit and souls are ill, we need to turn to virtues for the wise guidance and purifying.

\subsection{The Crisis of Moral Education and Medical Education: The Essential Cause Behind the Crisis of Health}

Essentially speaking, the physical conditions of an individual is determined by the results of all of his behaviors. As Plato put it in his classic book Republic" The human behavior flows from three main sources: desire, emotion, and knowledge."[4] Only by the wise and proper education, especially the proper moral education, can the behaviors of the people be proper. Nowadays, too much attention has been paid to the education of the practical knowledge and skills, with the moral education about how to manage and control the desires and emotions of the people being largely marginalized and even being entirely ignored. The enlightenment of virtues is what is fundamentally needed in both the health and happiness of a person.

Due to the unhealthy development of the medical education, the life ethics that is supposed to be concerned with the whole health and the whole happiness of the whole life has been replaced by the narrow technical education of medical skills or medicine knowledge. Undoubtedly, with the amazing development of industrialism and modernity, the vulgar utilitarianism has dominated the modern education, including the moral education. Consequently, we have overemphasized the practical skills and the practical knowledge that can be measured and calculated, entirely ignoring the great virtuous wisdom and morality that can essentially guide us to live the truly good life.

\section{From Virtuous Agents to Virtuous Environment: The Healing Power of Moral Context}

During the Renaissance period, people were simply enthusiastic about the human body and they passionately expressed their appreciation and admiration for the human body. But, with the modern life becoming increasingly modernized and commercial, the human being is no longer divine and sacred. In other words, the human being has been dehumanized and alienated. In Paul Tillich' colorful phrase, both the traditional world and the man have been "disenchanted". [5]

In some sense, the real, traditional and whole person has been declared to be dead by the crisis of modernity and the mechanical world. As a result of the influential idea of dichotomy proposed by Descartes, the body has been separated from mind, and even worse, the biological life has been isolated from the spiritual life. The general decline of the morality among the public has directly and fundamentally resulted in the disorientation and disintegration of the modern people, which, inevitably, has led to the crisis of the mental health of the modern people.

Neither the concept of health nor the concept of virtue is a timeless, unchanging, and eternal concept that can be profoundly understood without taking the factor of general social environment into account.

As Mac Intyre put it: "moral concepts are embodied in and are partially constitutive of forms of social life." Therefore, "the moral concepts and beliefs have to be studied historically and contextually." [6]

Without the necessary traditional and cultural roots serving as the solid foundation, and without the indispensable support from the continuous history of ethical and moral life, we will, inevitably and unavoidably, lose our sound understanding and comprehension, both theoretically and pragmatically, of the essence and significance attached to virtues and health. Neither virtue nor health is just a specific discipline, like physics or chemistry. On the contrary, both virtue and health are concerned with the ultimate issues of life: How shall we live and who we shall be.

\subsection{Be Connected and Overcome the Sense of Isolation: Creating the Harmonious Environment for Health}

One imperative and essential, integral part of human nature is the psychological need to be connected with others. The energy of life is supposed to flow not only within the life of the people, but also between the life of the people. According to Erich $\mathrm{H}$. Fromm, "To feel completely alone and isolated leads to mental disintegration just as physical starvation leads to death." [7] Since man has a deep fear for aloneness, man needs to live in the society and need to find the sense of being socially connected with each other. By being linked with others in one way or another, people get the warm energy of life to maintain his health.

How can the modern people be lonely, you may wonder, since the rapid development of science and technology, especially the communication technology has made it possible for us to live in a global village? The fundamental cause lies in what we call "moral aloneness" or virtuous isolation. This lack of relatedness to values, meanings of life and the mission of life has led to the silent desperation for most of the modern people. The cold logic of market competition has invaded into the sacred or emotional areas of the life, such as education, family, and marriage. When the feeling of virtuous isolation transcends a certain limit, it will lead to "the state of insanity which schizophrenic disturbances represent."[8] To overcome the prevalent sense of virtuous isolation, we need to restore the traditional virtues and restore the dignity of virtues.

\subsection{Virtues Make Us Search for the Meaning of Life: The Basis of Health}

Being thrown into the huge modern society, a person is fully aware of his individual existence, that is to say, he is completely aware of who he is as a lonely and fragile, limited creature in the unlimited, huge universe. On the one hand, he is aware of his greatness and glory, for his being able to think and feel; on the other hand, he is aware of his limits and mortality, knowing that 
sooner or later, he will die one day. "By being aware, even very dimly, of death, sickness, aging, he necessarily feels his insignificance and smallness in comparison with the universe and all others who are not he." [9] Virtues, essentially, mean to be kind to life, both to his own life and to others' life. The process of searching for the meaning and value of life is also the process of building the virtues and building the health. As Confucius said,"If a man were to set his heart on benevolence, he would be free from evil." [10] By building the virtues and living the virtuous life consistently, we can be mentally and spiritually immunized to the negative factors that can cause the illnesses.

\section{Appendix}

This study was supported by Nanjing University of Traditional Chinese Medicine (Grant No.NZYJG2013-18)

\section{References}

[1] The Discourses of Epictetus, edited by Christopher Gill, Published by J. M. Dent Orison Publishing Group, 1995, p. xix.
[2] Ernst Cassirer: An Essay on Man, Published by Yale University Press, 1944, p, 20.

[3] Alasdair Mac Intyre: After Virtue, Published by University of Notre Dame Press, Indiana,1981 ,p.2.

[4] Will Durant: The Story of Philosophy, Published by Simon and Schuster, New York, 1949, p.20.

[5] Rollo May: Man's Search for Himself, Published by W. W. Norton \& Company. Inc, New York, 1953, p, 70.

[6] After Mac Intyre, Edited by John Horton and Susan Mendus, Published by University of Notre Dame Press, Notre Dame, Indiana, 1994, p.5.

[7] Erich H. Fromm: Escape from Freedom, Published by Henry Holt and Company, New York, 1969, p.17.

[8] Erich H. Fromm: Escape from Freedom, Published by Henry Holt and Company, New York, 1969, p.17.

[9] Erich H. Fromm: Escape from Freedom, Published by Henry Holt and Company, New York, 1969, p.20.

[10] Confucius: The Analects, Published by Zhong Hua Book Company, Translated by D. C. Lau, 1988, p.50. 